\title{
Functional hyposplenism following allogeneic bone marrow transplantation
}

\author{
R J G Cuthbert, A Iqbal, A Gates, P J Toghill, N H Russell
}

\begin{abstract}
Aims-To investigate the incidence of functional hyposplenism in a group of patients who had undergone allogeneic bone marrow transplantation (BMT). Methods-Splenic function was assessed by counting the number of gluteraldehyde fixed red blood cells containing pits or indentations as examined by interference phase microscopy. Normal values are $<2 \%$ whereas splenectomy patients have values of 25 to $40 \%$.

Results-Twenty eight BMT recipients (17 men, 11 women) were studied at varying periods post-transplant and the results compared with 20 healthy volunteers and 10 patients who had undergone splenectomy or had splenic atrophy because of haematological conditions. Of the 28 BMT recipients, one had undergone a prior splenectomy; of the remaining 27 patients, four $(15 \%)$ had evidence of functional hyposplenism with between 5.0 and $34.0 \%$ pitted cells. Of these four patients, one had active extensive chronic graft versus host disease (GvHD) which has been previously reported to be associated with functional hyposplenism following transplantation. Only one of the four patients had peripheral blood red cell changes typical of hyposplenism.

Conclusion-These results confirm that extensive chronic GvHD is associated with hyposplenism. Intermediate degrees of functional hyposplenism may also occur following BMT in the absence of chronic GvHD and in the absence of haematological features of hyposplenism on routine blood films. This may be of significance in mediating the susceptibility to infection with encapsulating bacteria seen following allogeneic BMT.

(f Clin Pathol 1995;48:257-259)
\end{abstract}

Keywords: Hyposplenism, bone marrow transplantation, red cell pits.

Infection with encapsulated bacteria, particularly pneumococci, is a well recognised late complication following allogeneic bone marrow transplation (BMT). ${ }^{12}$ The risk of serious infection is greatest in patients who develop chronic graft versus host disease (GvHD). ${ }^{3}$ Immunoglobulin deficiency, especially IgG subclasses 2 and 4, may be associated with an impaired immune response to pneumococci and other encapsulated bacteria. ${ }^{14}$ Such immunoglobulin deficiency occurs most fre- quently in patients with chronic GvHD. ${ }^{5}$ Kalhs et al have reported the occurrence of functional asplenia in patients with chronic GvHD, which may also contribute to the increased susceptibility to bacterial infections seen in these patients. ${ }^{67}$

Functional hyposplenism has been reported in a number of patient groups including those with sickle cell disease, coeliac disease, inflammatory bowel disease, and amyloidosis. These patients, and also those who have undergone splenectomy, are known to have an increased susceptibility to infections with encapsulated bacteria.

Severe functional hyposplenism, splenic atrophy and splenectomy are associated with the presence of characteristic morphological changes in red blood cells, including HowellJolly bodies, acanthocytes, crenated cells, target cells, and spherocytes. With partial splenic dysfunction, these characteristic changes may not be observed and lesser degrees of hyposplenism may only be detected using indium labelled scintiscanning.

Corazza et $a l^{8}$ have described a simple differential interference contrast microscopic technique in which red cell indentations or pits, normally removed by the spleen, can be detected. These pits contain vacuoles with ferritin, haemoglobin and mitochrondrial remnants. ${ }^{9}$ The technique has been shown to be significantly more sensitive than detection of Howell-Jolly bodies on blood films, and correlates well with the degree of hyposplenism as assessed by scintiscans. ${ }^{8}$ We have applied this technique to investigate the prevalence of functional hyposplenism in long term survivors following allogeneic BMT.

\section{Methods}

The study group consisted of patients who had survived at least six months following allogeneic BMT. As many long term survivors become infrequent attenders at follow up clinics, the study group does not consist of consecutively transplanted patients. The study design was a cross-sectional survey based on single samples taken at routine follow up. Results were compared with a group of 20 healthy volunteers (median age 33 years, range $21-50$ years) and 10 patients who had undergone splenectomy or had established hyposplenism (median age 33 years, range $10-75$ years). In the latter group four patients had undergone splenectomy for immune thrombocytopenia and two for lymphoma or leukaemia, and four patients had splenic atrophy caused by sickle cell disease. 
Clinical details and percentage pitted red cell counts in 28 BMT recipients

\begin{tabular}{|c|c|c|c|c|c|c|c|}
\hline Case No. & Age/sex & Diagnosis & Months post-BMT & Acute GvHD & Chronic GvHD & Red cell pits (\%) & Comments \\
\hline 1 & $41 / \mathrm{F}$ & AML & 84 & - & \multirow{4}{*}{ Extensive } & 0.6 & \multirow{3}{*}{ Chronic GvHD resolved } \\
\hline 2 & $23 / M$ & ALL & 66 & - & & $0 \cdot 7$ & \\
\hline 3 & $37 / \mathrm{F}$ & AML & 61 & - & & 1.5 & \\
\hline 4 & $21 / M$ & AML & 58 & - & & $0 \cdot 3$ & \\
\hline 5 & $40 / M$ & MDS & 53 & - & \multirow[t]{2}{*}{ Limited } & 29 & \multirow[t]{22}{*}{ Splenectomy } \\
\hline 6 & $46 / M$ & $\mathrm{MM}$ & 37 & I & & 0.9 & \\
\hline 7 & 47/M & AML & 35 & - & & $1 \cdot 2$ & \\
\hline 8 & $42 / \mathrm{M}$ & AML & 34 & I & & 1.0 & \\
\hline 9 & $17 / \mathrm{M}$ & AML & 33 & - & & $5 \cdot 0$ & \\
\hline 10 & $25 / M$ & AML & 32 & - & & $1 \cdot 0$ & \\
\hline 11 & $31 / \mathrm{F}$ & AML & 32 & - & & 0.6 & \\
\hline 12 & $41 / M$ & $\mathrm{CML}$ & 28 & - & & $0 \cdot 3$ & \\
\hline 13 & $44 / \mathrm{F}$ & $\mathrm{MM}$ & 25 & - & & 0.9 & \\
\hline 14 & $29 / F$ & CML & 24 & I & & $1 \cdot 5$ & \\
\hline 15 & $48 / F$ & MDS & 22 & - & Extensive & 34 & \\
\hline 16 & $52 / \mathrm{F}$ & $M M$ & 21 & - & & $7 \cdot 0$ & \\
\hline 17 & $26 / M$ & AML & 19 & - & & $0 \cdot 6$ & \\
\hline 18 & $42 / \mathrm{M}$ & AML & 18 & I & & 0.5 & \\
\hline 19 & $15 / \mathrm{M}$ & ALL & 16 & - & & $1 \cdot 3$ & \\
\hline 20 & $36 / \mathrm{M}$ & $\mathrm{CML}$ & 16 & - & & 1.0 & \\
\hline 21 & $40 / M$ & MDS & 15 & - & & 0.6 & \\
\hline 22 & $49 / \mathrm{F}$ & $\mathrm{MM}$ & 13 & I & & $1 \cdot 8$ & \\
\hline 23 & $22 / M$ & SAA & 13 & I & & 0.9 & \\
\hline 24 & $29 / M$ & CML & 10 & - & \multirow{3}{*}{ Limited } & $1 \cdot 3$ & \\
\hline 25 & $45 / \mathrm{M}$ & ALL & 9 & - & & $5 \cdot 0$ & \\
\hline 26 & $50 / M$ & $\mathrm{MM}$ & 8 & - & & 0.5 & \\
\hline 27 & $40 / \mathrm{M}$ & CML & 8 & - & \multirow[t]{2}{*}{ Limited } & $1 \cdot 0$ & \multirow[t]{2}{*}{ BOOP } \\
\hline 28 & $43 / \mathrm{F}$ & AML & 7 & - & & $0 \cdot 3$ & \\
\hline
\end{tabular}

AML, acute myelobastic leukaemia; ALL, acute lymphoblastic leukaemia; CML, chronic myeloid leukaemia; MDS, myelodysplastic syndrome; MM, multiple myeloma; SAA, severe aplastic anaemia; BOOP, bronchiolitis obliterans with organising pneumonia.

All patients underwent BMT for haematological malignancies or severe aplastic anaemia. The conditioning regimen consisted of cyclophosphamide $120 \mathrm{mg} / \mathrm{kg}$ and fractionated total body irradiation (12 Gy). Cyclosporin and methotrexate were administered for GvHD prophylaxis according to our previously published regimen. ${ }^{10}$

Blood films stained using a Romanovsky technique were reviewed for the presence of Howell-Jolly bodies and the other characteristics of functional asplenia. Splenic func-

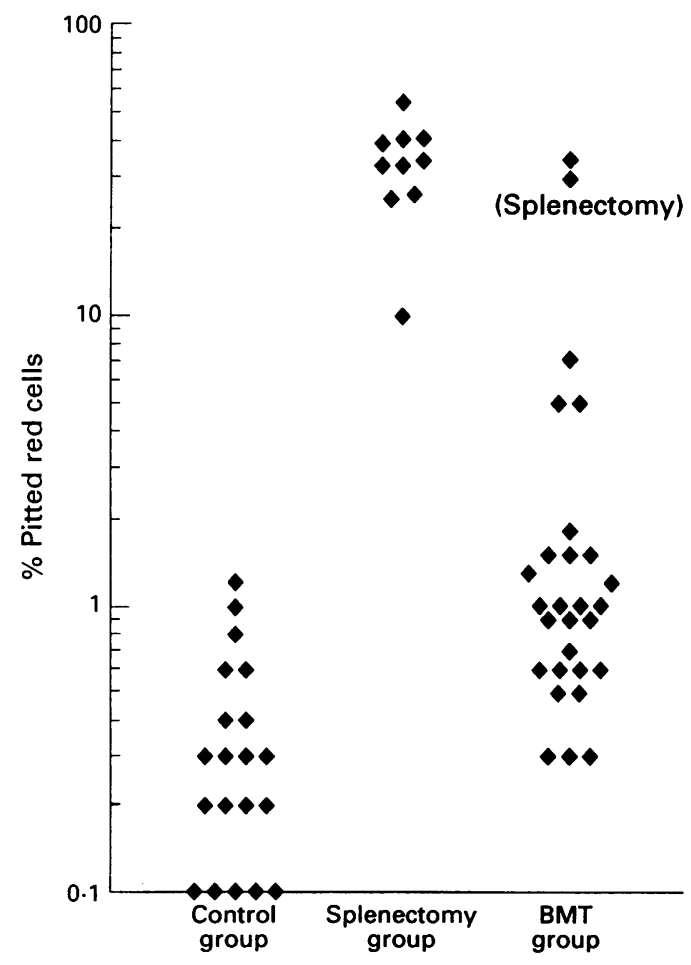

Distribution of percentage of red cells with pits in 28 allogeneic BMT recipients compared with a group of normal controls $(n=20)$ and a group of patients who had undergone splenectomy or had splenic atrophy caused by sickle cell disease $(n=10)$. tion was further studied by counting the number of red cell pits according to the method of Corazza et $a l^{8}$ A wet preparation of one drop of peripheral blood mixed with $0.5 \mathrm{ml}$ $3 \%$ gluteraldahyde buffered to $\mathrm{pH} 7 \cdot 4$ was examined by interference phase contrast microscopy. One thousand red cells were examined to determine the percentage with such pits (normal $<2 \%$ ). All samples were processed and examined by a single observer (AG).

The Mann-Whitney U test was used to compare results between the patient group and the control group.

\section{Results}

The patient group comprised 28 allogeneic BMT recipients (17 women and 11 men). The median age at BMT was 40 years (range 15-52 years). Median follow up was 25 months (range 10-85 months). The clinical details including diagnosis at BMT and incidence of acute and chronic GvHD are outlined in the table. Six patients developed grade I acute GvHD. Active extensive chronic GvHD was present in one patient (case 15) at the time of the study. One patient (case 2) had extensive chronic GvHD which was in clinical remission. Two patients had limited stage chronic GvHD (cases 25 and 27 ); case 27 subsequently developed bronchiolitis obliterans with organising pneumonia.

Although recurrent minor bacterial infections occurred in three patients, none had serious bacterial infection 100 days post-BMT. However, one patient at our centre died of pneumococcal septicaemia one year postBMT, before the current study was undertaken.

The figure shows the distribution of pitted red cell counts in the study group compared with healthy volunteers and patients who had undergone a splenectomy. Twenty three BMT recipients had pitted red cell counts of $<2 \%$ whereas five patients had results above normal. One patient from this group had previously had a splenectomy for staging of Hodgkin's 
disease (case 5) and was excluded from further analysis. Thus, four of $27(15 \%)$ BMT recipients had evidence of functional hyposplenism. As a group, the BMT recipients had significantly higher pitted red cell counts than the normal controls $(U=4.34 ; p<0 \cdot 001)$. During the study, only two BMT recipients had Howell-Jolly bodies detectable on peripheral blood films (case 5 (previous splenectomy) and case 15 (active extensive chronic GvHD)).

\section{Discussion}

The prevalence of both acute and chronic GvHD was low in the study group, which is consistent with our previously published experience. ${ }^{10}$ Functional asplenia was observed in the one patient who had active extensive chronic GvHD, consistent with the report by Kahls et al. ${ }^{6}$ However, the technique used for assessing splenic hypofunction by measuring pitted red cell counts is more sensitive than detection of Howell-Jolly bodies on peripheral blood films. Thus, we were able to identify patients with normal blood films who had intermediate degrees of functional hyposplenism and who did not have active extensive chronic GvHD.

As this technique is very simple to perform, regular follow up samples can easily be organised. Therefore, prospective evaluation of splenic function in BMT recipients could be conducted. This data may be of value in determining which patients should be offered long term antibiotic prophylaxis against encapsulated bacteria. We are currently undertaking such a prospective study of the significance of splenic dysfunction in mediating the susceptibility to bacterial infection following BMT.
Our current policy is to recommend penicillin $\mathrm{V}$ prophylaxis to all patients for a minimum of two years following BMT. At one year, we recommend polyvalent pneumococcal and $H$ influenzae type b vaccination. Patients who develop extensive GvHD are maintained on penicillin $\mathrm{V}$ prophylaxis, as antibody responses to vaccination are impaired. Assessment of splenic function at regular intervals could be of additional value in determining patients without chronic GvHD who may benefit from penicillin $\mathrm{V}$ prophylaxis for more than two years.

1 Sheridan JF, Tutschka PJ, Sedmak DD, Copelan EA. Immunoglobulin $G$ subclass deficiency and pneumococcal infection after allogeneic bone marrow transplantation. Blood 1990;75:1583-6.

2 Atkinson K, Storb R, Prentice RL, Weiden PL, Witherspoon $\mathrm{RP}$, Sullivan $\mathrm{K}$, et al. Analysis of late infections in 89 longterm survivors of bone marrow transplantation. Blood term survivors of

3 Sullivan KM, Shulman HM, Storb R, Weiden PL, Witherspoon RP, McDonald GB, et al. Chronic graft versus host disease in 52 patients: Adverse natural cause and successful treatment with combination immunosuppression. Blood 1981;57:267-76.

4 Barrett DJ, Ayoub EM. IgG2 subclass restriction of antibody to pneumococcal polysaccharides. Clin Exp Immunol 1986; 63:127-34.

5 Witherspoon RP, Storb R, Ochs HD, Fluornoy N, Kopecky $\mathrm{KJ}$, Sullivan KM, et al. Recovery of antibody production in human allogeneic marrow graft recipients: influence of time post-transplantation, the presence or absence of chronic graft-versus-host disease, and anti-thymocyte globulin treatment. Blood 1981;58:360-8.

6 Kalhs P, Panser S, Kletter K, Minar E, Stain-Kos M Walhs P, Panser S, Kletter K, Minar E, Stain-Kos $M$,
Walter R, et al. Functional asplenia after bone marrow transplantation: A late complication related to extensive chronic graft-versus-host disease. Ann Intern Med, 1988; 109:461-4.

7 Kalhs $P$, Kier P, Lechner K. Functional asplenia after bone marrow transplantation. Ann Intern Med, 1990;113:805-6.

8 Corazza GR, Bullen AW, Hall R, Robinson PJ, Losowsky MS. Simple method of assessing splenic function of coeliac disease. Clin Sci 1981;60:109-13.

9 Schmitzen B, Rucknagel DL, Spencer HH, Aikawa M. Erythrocyte pits and vacuoles as seen with transmission and scanning election microscopy. Science 1971;173:2512.

10 Hunter AE, Bessell EM, Russell NH. Effective prevention of acute graft versus host disease following allogeneic bone marrow transplantation with low leukaemic relapse using methotrexate and therapeutically monitored levels of cyclosporin. Bone Marrow Transplant 1992;10:431-4. 